\title{
Personalized Resource Recommendation System Design for Teachers Training
}

\author{
Dan Dan Wei ${ }^{1, a^{*}}$, Le Xing Qiü, b \\ 1 Education College, Jiangxi Science and Technology Normal University, Nanchang, China \\ 2 Educational Technology Center, Nan Chang Army College, Nanchang, China \\ aqlxwdd@163.com, ${ }^{\text {b } q 1 x 98 @ t o m . c o m ~}$
}

\begin{abstract}
Keywords: Personalized; Resource Recommend; System design
Abstract. With the integration of computer technology, network technology and mobile communication technology continuously, the formation of personalized resource recommendation has become possible. Based on teachers' demand investigation and analysis, this paper analyzes the teacher system architecture, personalized resource recommendation and service safeguard mechanism.
\end{abstract}

\section{Introduction}

Along with the computer technology, network technology and mobile communication technology integrate continuously, the formation of personalized resource recommendation has become possible. Personalized resources push has been embodied in the electronic commerce (such as taobao station, etc.), social media, (such as QQ, etc.), in the face of huge amounts of digital education resources, resources push is a new mechanism that the user of the digital education resources access to the resources needed in the learning activities.

Although teacher training work is in full swing in our country, but there are also many problems. In the training, one is the lack of standard and long-term training plan; Second, the number that the teacher training base can provide services of teachers is limited, and single function, unable to meet the demand of the education and training of teachers; Third, training content lacks of autonomy and individuality, no independent choice of training content, a lot of training as a condition of task, evaluation, evaluation standard must be completed, and because of the shortage of training resources, teachers' professional selection is very limited, therefore lack for personalized for individual teacher's professional development of teachers' training content, few teachers individual training needs is paid attention. [1] Therefore, paying attention to the personalized resource recommendation in the teacher training will help improve the teacher training system, actively promote the modern training means, and provide the guarantee conditions for strengthening teacher training work.

\section{Personalized Information Pushing Service}

Resources Push is a mechanism that the learners obtain resources needs in the learning activities. The most important feature of "Push" is the server sending information, its advantage lies in the initiative and timeliness of information. In the process of resources in a push for different users (learners) object, should push the different resources differ from man to man, this resource push called "personalized pushing service". [2]

Resources characteristic of push service: [3]

The Timely Initiative. This is the most basic characteristic of push services, i.e. when a new resources need to be submitted, according to the type and importance of transmission resources, push the software will take the initiative to remind the user to receive new resources. In order to improve the timeliness that user access to resources.

For The Purpose. Push service to provide the resources customize according to the specific user needs, which fully reflects the individual needs of users. This personalized service is dynamic, users 
only need to describe the resource requirements in the custom at the beginning, the push software will automatically track the user's intended use, push specific resources in real-time.

Integration. In push service, teaching staff from various channels, access to information through various means, and carry on the processing and integration, through the fixed channel transmitted to the user, the processing resources is obviously more comprehensive, more accuracy.

Convenient Efficiency. Users only need to input a resource request, then obtain resources service continuously. Push service also uses resource proxy mechanism, can automatically track the user resource requirements. Such notification service saves the user accessing time actively, and reduces the redundant resources, improve the matching degree of the resources, thus greatly facilitate the users, and improve the efficiency.

\section{Teachers' Personalized Resources to Push System Design}

The Thought of System Design. The teacher through the corresponding terminal, acquire professional development resources required from the system resource platform. In teacher national training network such as infant or primary and secondary school, in China's vocational education teachers' training website or the National university teachers' training website embedding such resources push system. System resources can meet the teachers to achieve the informal learning.

Investigation and analysis of demand push system with personal professional development of teachers in teacher training resources, teacher training is a long-term or even lifelong, especially the teachers of vocational education, because education occupation is in a change of development for a long time. But the post training of teachers lack the training plan of sustainable development. Analysis of teachers' professional development needs, system platform plate set in the teachers' professional development needs survey, according to the survey results adding appropriate training content. Lay a foundation for teachers to provide personalized training services.

The teacher register the corresponding training site, input the basic personal information, proposes the personalized demand, can receive personalized support services. Relying on the mobile network media such as the mobile phone, to receive regularly send personalized needs. The network server according to the requirements, test education resource library, matching the demand resources by sending teachers through teachers' specified way, if there is no corresponding resources, then timely development.

The Design of System Function Module. Based on the above system design idea, teacher's personalized learning resources to push system function design are shown in figure 1 below.

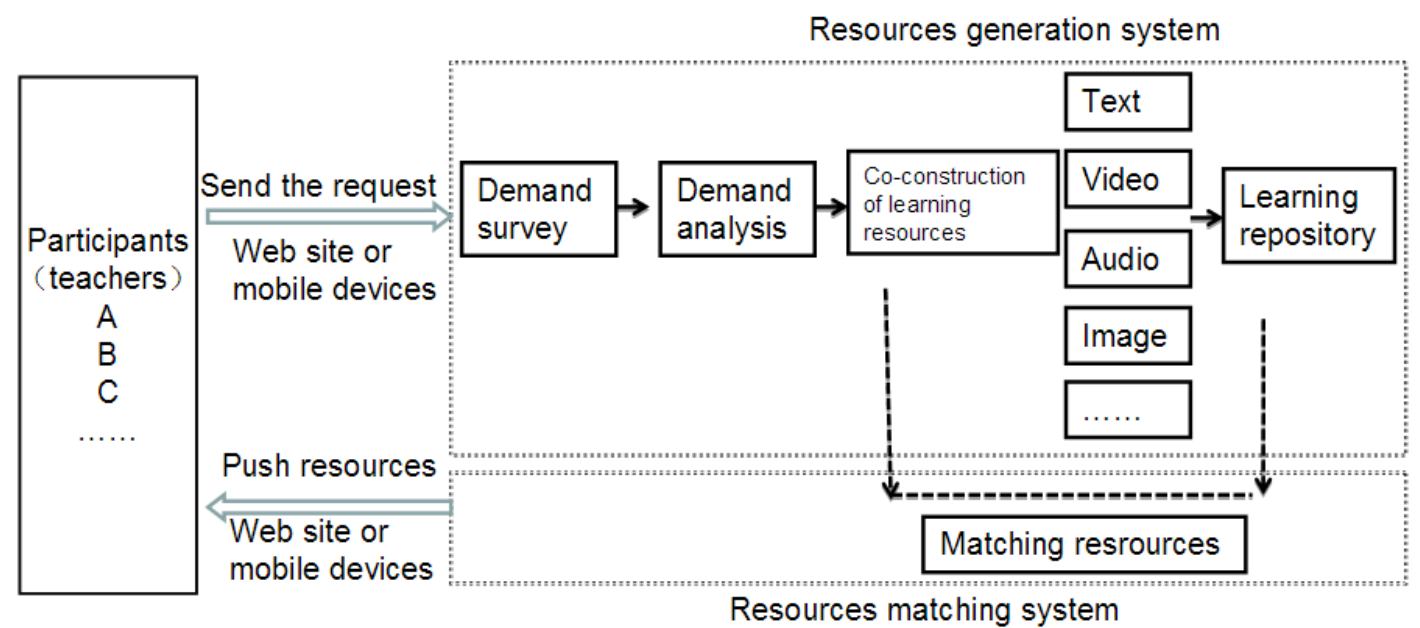

Figure1. Personalized learning resources in teacher training system

The System Function. The basic process of information push service is user information demand understanding, thematic information search, information regularly feedback.[4] First the user input its 
information needs to the system, this includes user profile information, user interested information subject, and then the system or manual search on the Internet purposefully, finally regularly relevant information will be pushed to the user on the host.

Learners just reserve good learning resources in the original custom stage, mobile devices can interact with the server invisible and actively. The system automatically completes the comparison and transmit of various numbers in the running process, identify the location of the learners and push the right resources as the location change.

Due to the study emphasis of different learners themselves, thus the type of resources will have different requirements. This system can combine the personalized demand of learners and actively push the appropriate resources, provides the mobile learning model to the learner oriented.

System incorporate learning environment on the natural environment, push against the current situation of the resources, so learners in learning keep close contact with the external environment, and promote the rapid transformation of the knowledge.

Systems support teachers design, development and application of mobile learning resources.

The Types of Personalized Resources Pushing. From the perspective of the properties of resource, can be divided into text, image, audio, video, animation, etc.;

Distinguish from the category of professional development resources of teacher, which can be divided into information technology resources, knowledge resources, professional knowledge resources;

According to the property and the management level to distinguish, they can be divided into national resources, local resources and personal resources.

The implementation of personalized resources push mechanism benefit from the analysis of a relationship between people and resources. What kind of resources can be pushed to the man? A person, like what kind of resources? This kind of question is a personalized demanding problem. We need to analysis "people", "resource" the two element, and find out the relation between them.

Personalized information push service based on the network platform, resources in the platform involves digital resources in the use of Teacher Education in teaching, should be adopted to academic and professional settings as the basis. The resource attribute description can include the subject classification, professional description. In the resource attribute the result set contains the resource name, author, keywords, description of resources, the subject (classification), which belongs to the professional, the research direction (equivalent professional direction), information application. In the attribute information to some information and "human" attribute description are closely related, such as professional direction, research direction.

Personalized Resources Pushing Channel. Here prominent is active service information, namely the change "people find information" for "information for someone", through the mail, "channel", Webpage submit reservation, mobile phone message and other means to send information to the people.[5] At present, many information service institutions introduce such as personalized custom channel, personal intelligent search agent etc.

Intelligent Resources Recommend. This pushing form can be used to conduct statistical analysis, is a kind of Applied Statistics on the number of relation analysis method, by getting a certain time in the teachers click the number and distribution to analysis the behavior of the trend. As in the teacher after logging system, the system records the browsing and downloading quantity and analysis of resources (mainly by recording the number and distribution of the mouse clicking event). In the record number of reaches a certain value to satisfy the requirement of the principle of statistics, we can predict the behavior tendency, such as teachers would like such resources, may be a professional learning, may be some aspects such as its research direction etc. The predicted results in Teachers' attribute set, when it again after logging system, it can push to its meet the conditions of resources attribute in the result set. [6]

Semi Intelligent Resources Recommend. This push form can use predefined pattern analysis method, is through the adoption of a accord with common sense to define a "person" descriptions of people attribute pattern that compulsory norms. Usually the understanding of people is gradually from 
outside to inside, and outside, such as name, age, gender, appearance, Internal such as interests, personal experience (including life, learning, and emotional), career, etc. This information is a description of people, can serve as a kind of attribute information storage of attribute in the result set.

In the attribute information, and the nature of information resources, such as learning experience (this may include its specialty, research direction, etc.), career, etc. Developing the professional learning, and learning requires the related learning resources, professional property and resources, and learning experience (major), research direction and resource attributes (professional, research direction) creates a connection between. These associated attribute information can be as associated query conditions so as to realize the personalized push of resources. [7]

\section{The Safeguard Mechanism of Personalized Resources Recommendation in Teacher Training}

The personalized information pushing service in teacher training, needs long-term participation in government, teacher training colleges and enterprises. Such as: The governments give policy, financial support. Training institutions provide specific training services, including professional knowledge training. And enterprises give the chance of practical training, which need to actively guide all kinds of enterprise participation.

In the occupation education development, school-enterprise cooperation is the development pattern of complementary advantages, and fully mobilize the enthusiasm of enterprises, enterprises play a practice base, is the key to a good occupation education. Enterprises participate in. The current teacher training institutions is in a single, related work is implemented in colleges and universities, this benefit is conducive to the theory of ability training of teachers, but not with combination of enterprise training, post training effect is not obvious, the function of the enterprises involved in teacher training is to get the development and utilization.

\section{Summary}

To keep the sustainable development of teachers in training, we need introduce the concept of personalized service and personalized recommendation technology into the training system, to form resources self- generating, resources co-construction, resource matching and pushing, which requires the support and participation of all sectors of society. To maximize the formation of teacher training performance.

\section{References}

[1] Tang Zhibin, Shi Weiping, The international perspective of the construction of the teachers in China: problems and solutions. Teacher education research(2012)

[2] [6] [7] Wang Liang, Xu Ming, Digital Resources supermarket "personalized information pushing" design and implementation. The modern education technology(2011)

[3] Information

Push

Services.

http://baike.baidu.com/link?url=HouulDWQ5VaMAYiCXMjaGTjerC-VlW

1C6siUWh0Ehik1YP4OqpuJYeOE8_N9hfuPatsp232jfPiFq59b4wdHeK(2014)

[4] Cheng Jiejing, Personalized Information Resource Service Preliminary Approach Under the Network Environment, Journal of Modern Information(2011)

[5] Gao Xia, Academic Exchanges In the Face of the Network Era and the Technology Innovation era, http://www.kjlw.cn/shownew.asp?newsid=932(2009) 